\title{
APPLICATION OF SUPER ABSORBENT POLYMER IN FLOOD MANAGEMENT AND AGRICULTURAL WATER MANAGEMENT
}

\author{
M. S. Bhagat ${ }^{1}$, A. D. Ghare'and R.V. Ralegaonkar ${ }^{3}$ \\ ${ }^{1}$ Assistant Professor, Department of Civil Engineering YCCE, Nagpur \\ ${ }^{2,3}$ Associate Professor, Department of Civil EngineeringVNIT, Nagpur \\ \{1Email:madhurikene@yahoo.co.in, ${ }^{2}$ msbciv@gmail.com\}
}

\begin{abstract}
Superabsorbent polymers (SAP) are hydrophilic materials that can absorb and retain huge amounts of water. The absorbency varies from 100 to 400 times depending on environmental conditions. The material absorbs water and swells. It is analyzed through experimentation that the permeability of the swelled material is within limits of semi pervious material. So it can be used for retaining the flood water and manage low to moderate floods. Specifically, it can be used for managing low to moderate floods of agricultural farm lands. The disposal of the material is the main difficulty which can be solved out by using it in agriculture. Agriculture is the basic need to survive on earth. However due to extreme havoc of the environment, the survival of the farmers became difficult. So, the farmers started diverting their profession. Many farmers sold out their agricultural lands due to environmental abnormalities. Heavy rainfall and water scarcity are the two extreme conditions in agriculture. Water scarcity is further accompanied by high temperature. In this paper, two concepts have been combined together. One is use of super absorbent polymer for moderate floods and other is use of its residue in agriculture. The residue or material can be effectively used in agricultural crops and reduce the water requirement by about $50 \%$.
\end{abstract}

Keywords: Superabsorbent Polymer (SAP), Hydrophilic, Residue

\section{Introduction}

Flooding is extremely dangerous and causes extensive damage to life and property. Prolonged, extensive rainfall is the main cause of flooding. Flood occurs when natural watercourses do not have the capacity to convey excess water. Floods also have a drastic effect on the agricultural and destroy various crops. Agriculture is the basic need to survive on earth. Throughout human history, agriculture has been a source of food, fuel and fiber [1]. However due to extreme havoc of the environment, the survival of the farmers became difficult. So, the farmers started diverting their profession. Many farmers sold out their agricultural lands due to environmental abnormalities. Water scarcity and heavy rainfall are the two extreme conditions in agriculture. Water scarcity is further accompanied by high temperature. Agricultural sector is one of the largest consumers of water. The method of irrigation practiced in large parts of the country is surface irrigation under which crop utilizes only less than one half of the water released and remaining half gets lost in conveyance, application, runoff and evaporation. High initial cost, inadequate subsidy amount, lack of availability of technical input, clogging of dripper and cracking of laterals, damages due to rats and squirrels, high cost of spares and components etc., are some of the major problems faced by farmers. Hence, there is a need of a new irrigation system, which requires less amount of water for the better production of crops. In view of this, Superabsorbent polymers (SAPs) are used for advance agriculture which reduces the amount of water needed for the crops and also reduces frequency of watering for arid and desert areas. Desertification is the degradation of land in arid, semi arid and dry areas resulting from various factors including climatic variations and human activities. It can be solved by the use of synthetic materials with good water absorption and retention capacities even under high pressure or temperature [2].

In this paper, two concepts have been combined together. One is use of super absorbent polymer for managing low to moderate floods and other is use of its residue in agriculture. The residue or material can be effectively used in agricultural crops and reduce the water requirement by about $60 \%$. The paper is outlined as under; first properties, technical features and significance of the material is presented. Then water absorption and swelling, permeability test, variation in moisture content and water requirement in plants has been described step by step.

\section{Material and Methods}

\subsection{Superabsorbent Polymer (SAP)}

Superabsorbent Polymers are the materials that have the ability to absorb and retain large volumes of water and aqueous solutions. The hydrated gel particles retain the absorbed water even under pressure. This unique ability to hold absorbed water, even against pressure, is the major advantage of using super absorbent polymers. It is a macro molecule polymer which is non-toxic, nonirritating and non-corrosive. It is natural, biodegradable starch-based formulation. It has greater water absorption potential and the ability to freely release water under atmospheric condition. SAP materials cannot return to their starting monomers, i.e., they are scientifically irreversible to toxic initiating materials [3]. SAP 
materials have their applications in medicine, biotechnology, pharmaceutical, veterinary, food industry, and agriculture technologies [4].

The common superabsorbent polymer is sodium polyacrylate made from partially neutralized acrylic acid. Sodium polyacrylate belongs to a family of water loving or hydrophilic polymers. There are two important groups that are found on the polymer chains, carbonyl $(\mathrm{COOH})$ and sodium $(\mathrm{Na})$. These two groups are important for water absorption. When the polymer is in the presence of a liquid, the sodium dissociates from the carbonyl group creating two ions, carboxyl (COO-) and sodium $(\mathrm{Na}+)$.
The carboxyl groups then begin to repel each other because they have the same negative charge. As a result of the repulsion between the like charges, the sodium polyacrylate chain uncoils or swells and forms a gel substance. The action of swelling allows more liquid to associate with the polymer chain. There are four major contributors to sodium polyacrylate's ability to absorb liquids or swell. These contributors are hydrophilic chains, charge repulsion, osmosis, and cross-links between chains. The cross-linked chains absorbs water and forms hydrated chains as shown in Fig. 1. It forms a three-dimensional network and prevents it from swelling to infinity i.e. dissolving [5].

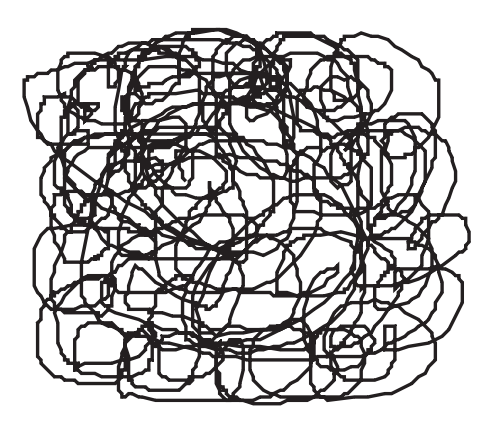

SAP in cross linked chains

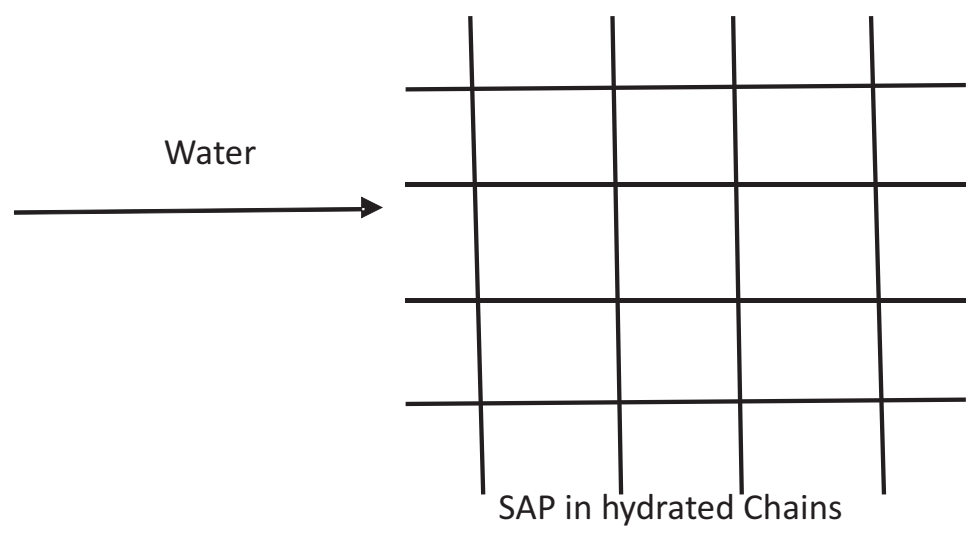

SAP in hydrated Chains

Fig. 1. SAP in cross-linked chains and hydrated chains

SAPs are made from chemically modified starch and cellulose and other polymers like poly vinyl alcohol (PVA) and poly ethylene oxide (PEO) which are hydrophilic and have high intake of water. When lightly cross-linked, these polymers became water swell-able but not water-soluble.

Many arid and semi arid regions are facing the problems of uncertain and inadequate rain fall. Spatially diversified soil characteristics, shortage of large agricultural lands and underprivileged condition of farmers do not allow them to adopt advantageous and economical application of traditional irrigation methods as well as micro irrigation techniques. Thus SAP can be utilized for increasing water use efficiency and enhancing crop yield. Soil conditioning with SAP could be an innovative method of agriculture, which works as diminutive water storage reservoirs. The technical features of an ideal SAP material are high absorption capacity in saline condition, low price and high biodegradability without forming toxic substances. The various properties of SAP have several advantages in flood control and agriculture. It is harmless and non-polluting with super water absorbing and water preserving ability while the absorbed water cannot be squeezed out easily and it can release and absorb water repeatedly. It can be used in agriculture and forestry and can form a micro reservoir at plants root. It can absorb natural water and can reach around 100-400 times by its self-weight. It also has better water-retention capacity. SAP can release and absorb water repeatedly, the water which it absorbs can be absorbed slowly by the seed and plant-root, so this will increase soil moisture effectively and decrease the times of irrigation. If the soil is not amended with polymer, the plants show signs of dehydration during water stress [6]. SAP when mixed with the soil structure create good air permeability in soil, improves water absorption property of soil and fertilizer conservation capacity hence economy in irrigation can be attained [7]. Use of SAP can save water and labour. SAP can be applied in the drought season, dry land, mountainous area, sloping field and desert to improve agriculture. SAP-amended soil can store a considerable amount of water and can release it gradually to the plant roots when needed. The adoption of the proposed SAP in cultivations could thus represent a promising solution for the rationalization of water resources, especially in desert

\subsection{Methods}

To evaluate different properties of the material, experimentation work has been carried out on water absorption, swelling, permeability, water retention in soil and water requirement in agricultural plants.

\subsubsection{Water Absorption And Swelling}

Water absorption and swelling are closely related to each other. SAP can absorb water to a great extent. By absorbing water, it gains the weight, which is useful parameter for retention. The increase in weight is 
correlated to the amount of water absorbed. One gram of SAP material may absorbs 100-400 grams of water depending on water quality. SAP absorb water hundreds times of its own weight and being converted to long lasting gels, have a special place in agriculture, landscaping, erosion control and desert reduction [9].

To verify water absorption and swelling, $1 \mathrm{gm}$ of SAP material was mixed with tap water gradually and the swelling pattern was observed carefully. Initially the swelling is high in 2-5 minutes (120-300 sec.), then is slowly swells and absorbs large quantity of water in about 20 minutes (1200). Finally it attains an equilibrium condition, i.e. no additional swelling with respect to time. Here water absorption ratio achieved was 1:260 i.e. $1 \mathrm{gm}$ of SAP material absorbs $260 \mathrm{gm}$ of water. Water absorption and swelling kinematics with respect to time was plotted as shown in Fig. 2.

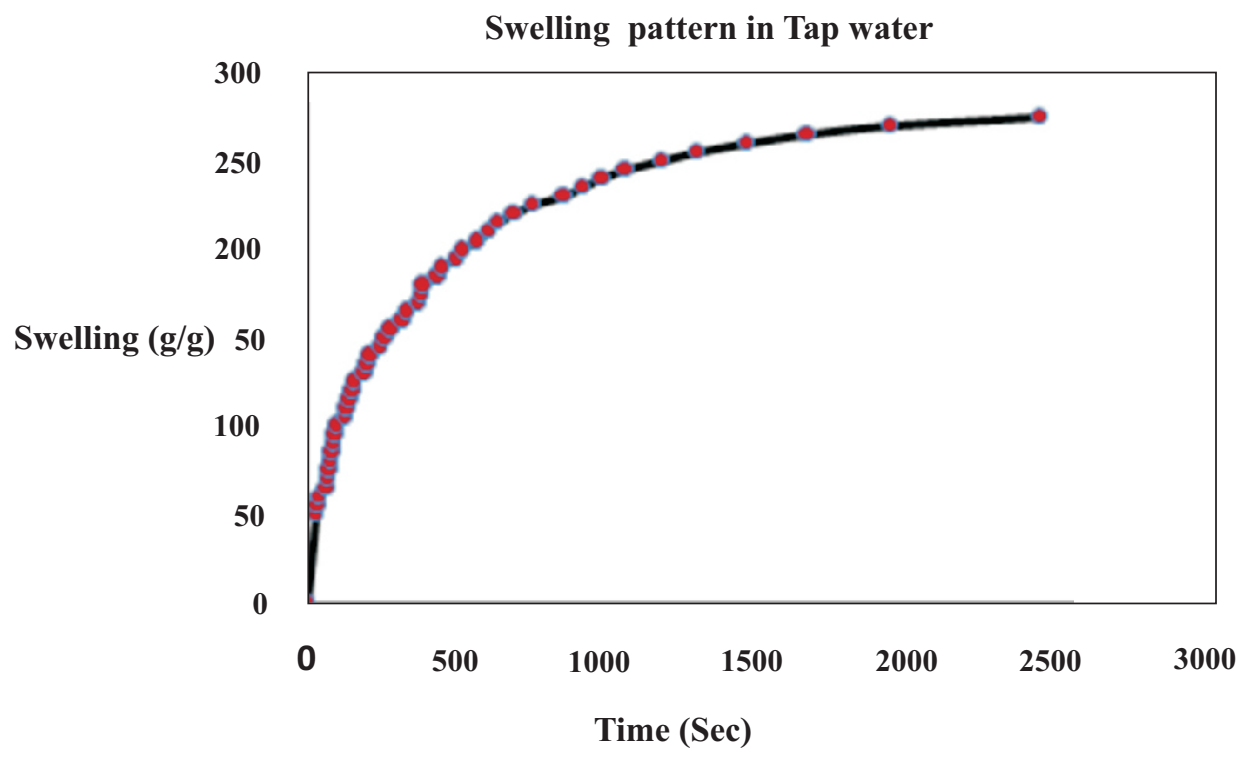

Fig. 2. Swelling pattern of tap water
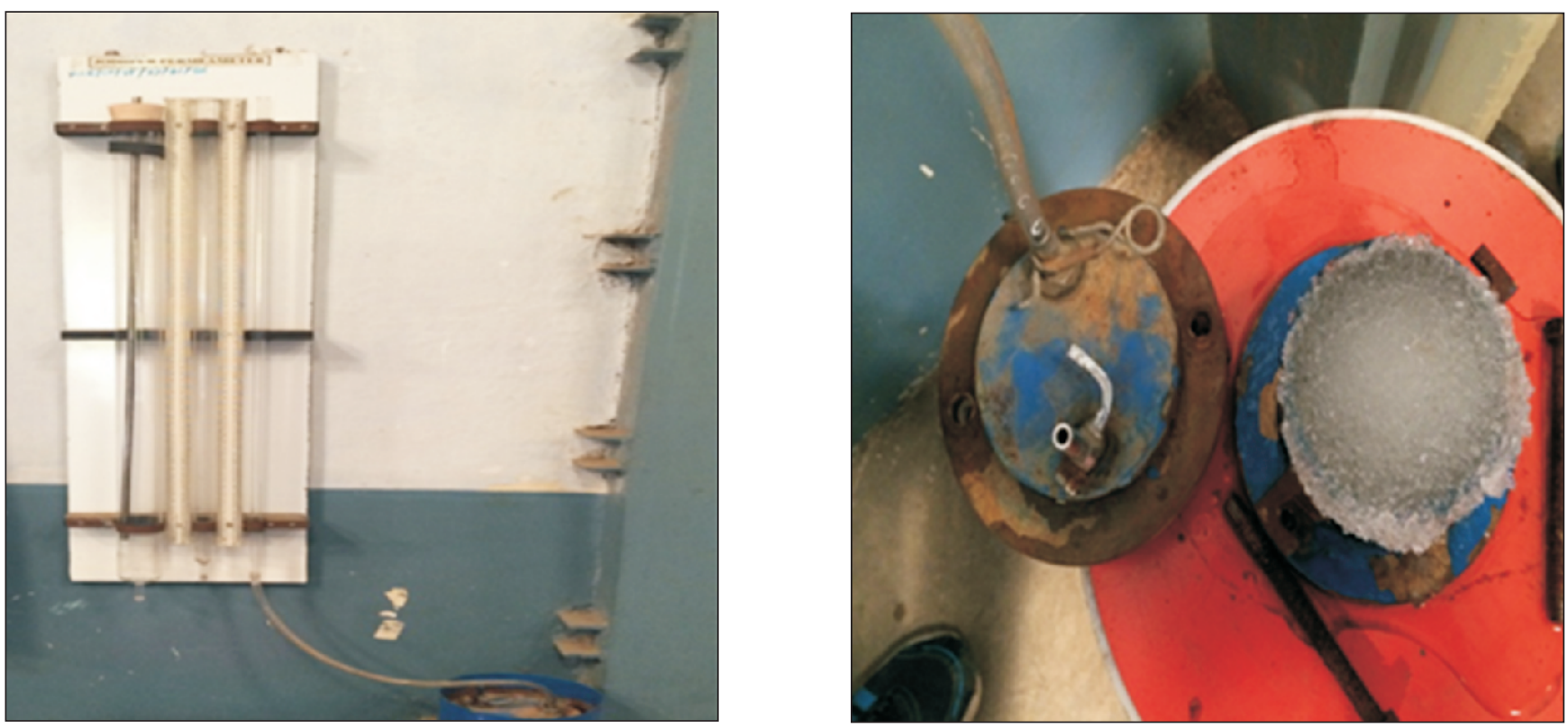

Fig. 3. Jodhpur Apparatus (Falling Head Permeability Test) 


\subsubsection{Permeability Test}

Permeability is defined as the property of passage or seepage of water through its interconnected voids. A material having continuous voids is called as permeable. Different materials have different permeability. The permeability of impervious soil sample is zero, permeability of semi pervious soil sample is 0.001 to 1 and permeability of pervious soil sample 1 to 100 . To check the retention capacity of swelled SAP material its permeability has been evaluated. The permeability has been evaluated for different SAP to water ratios. To determine the permeability Jodhpur apparatus of falling head permeability test was used as shown in Fig. 3.

The falling head permeability test is a common method to determine the permeability of fine-grained soils with intermediate and low permeability such as silts and clays. In this method, water is allowed to pass through a relatively short soil sample connected to a standpipe. Water heads or levels and volume of water passing through the sample were measured. The time required for water in the standpipe to move from the upper level to the lower level is recorded. The test was repeated for couple of times by refilling the standpipe containing the material. The recorded time should be the same for each test within an allowable variation of about $10 \%$. Different materials were prepared using different SAP to Water ratio. Different SAP to Water ratio considered were $1: 50,1: 75,1: 100,1: 125$ and 1:150.The permeability of the soil sample has been calculated using equation 1 as given below.

$$
\left.K=2.303 \text {. [a. } D_{s} /(A . t)\right] . \log \left(h_{1} / h_{2}\right)
$$

Where, $\mathrm{D}_{\mathrm{s}}$ is depth of the soil sample column measured as $6 \mathrm{~cm}$, A is sample cross section area measured as 50.26 $\mathrm{cm}^{2}$, a is cross section of the standpipe measured as 28.27 $\mathrm{cm}^{2}, \mathrm{t}$ is recorded time for the water column to flow though the sample measured as $5 \mathrm{sec}$ and $h_{1}$ and $h_{2}$ are upper and lower water level in the standpipe measured using the same water head reference pipe. The permeability of different materials of different SAP to Water ratio were determined and tabulated in Table 1.

Table1. Permeability of different SAP combinations

\begin{tabular}{|c|c|c|c|c|c|c|c|}
\hline Sr. no. & SAP:Water Ratio & $\mathrm{SAP}(\mathrm{gm})$ & Water $(\mathrm{ml})$ & $\mathrm{h}_{1}(\mathrm{~cm})$ & $\mathrm{h}_{2}(\mathrm{~cm})$ & $\mathrm{t}(\mathrm{sec})$ & $\mathrm{k}(\mathrm{cm} / \mathrm{s})$ \\
\hline 1. & $1: 50$ & 6 & 300 & 118.5 & 117.1 & 5 & 0.008 \\
\hline 2. & $1: 75$ & 4 & 300 & 118.5 & 116.5 & 5 & 0.011 \\
\hline 3. & $1: 100$ & 3 & 300 & 118.5 & 113.5 & 5 & 0.029 \\
\hline 4. & $1: 125$ & 2.4 & 300 & 118.5 & 111.5 & 5 & 0.041 \\
\hline 5. & $1: 150$ & 2 & 300 & 118.5 & 108.5 & 5 & 0.059 \\
\hline
\end{tabular}

The value of coefficient of Permeability (k) for different SAP to water ratio ranges in between 0.008 to 0.059 . These values of coefficient of Permeability $(\mathrm{k})$ are similar to those of semi-pervious materials. This indicates that the SAP material behaves as semi-pervious.

\subsubsection{Water Content of Soil with and without SAP}

Moisture content of soil is the measure of water content of soil. Moisture content of soil is the ratio of the weight of water present to the weight of dry soil in a given soil mass. It is usually expressed in percentage of the dry soil mass and is given by equation 2 as given below.

$$
\mathrm{w}=\left(\mathrm{M}_{2}-\mathrm{M}_{3) /}\left(\mathrm{M}_{3}-\mathrm{M}_{1}\right) * 100(\%)\right.
$$

Where; $M_{1}$ is weight of empty container, $M_{2}$ is weight of wet soil and weight of empty container and M3 is weight of oven dried soil and weight of empty container.

The soil sample was oven dried at standard temperature of $105^{\circ}$ to $110^{\circ} \mathrm{C}$ for 24 hours. Oven dried soil sample was mixed with same quantity of water with and without SAP material in two different containers. Then moisture content of these two soil samples was found for next 15 days by keeping both the soil samples in environmental conditions. Moisture content of soil sample with and without SAP material is tabulated in Table 2 and Table 3 respectively. The comparison of soil sample with and without SAP material is tabulated in Table 4. The pictorial view of soil sample with and without SAP material at the end of experimentation is given Fig. 4.

Table 2. Moisture content of soil sample with SAP

\begin{tabular}{|c|c|c|c|c|}
\hline Time (Days) & $\mathbf{M}_{\mathbf{1}}(\mathbf{g m})$ & $\left.\mathbf{M}_{\mathbf{2}} \mathbf{( g m}\right)$ & $\left.\mathbf{M}_{\mathbf{3}} \mathbf{( g m}\right)$ & $\mathbf{W} \mathbf{( \% )}$ \\
\hline 1 & 15.01 & 78.3 & 61.89 & 35.00 \\
\hline 2 & 15.01 & 77.81 & 62.36 & 32.63 \\
\hline 3 & 15.01 & 105.55 & 83.76 & 31.69 \\
\hline 4 & 15.01 & 73.53 & 60.48 & 28.69 \\
\hline 5 & 15.01 & 68.53 & 57.43 & 26.17 \\
\hline 6 & 15.01 & 70.00 & 59.46 & 23.71 \\
\hline 7 & 15.01 & 72.83 & 62.86 & 20.83 \\
\hline 8 & 15.01 & 65.81 & 57.92 & 18.38 \\
\hline 9 & 15.01 & 62.05 & 55.30 & 16.75 \\
\hline 10 & 15.01 & 58.50 & 52.88 & 14.83 \\
\hline 11 & 15.01 & 49.20 & 45.24 & 13.09 \\
\hline 12 & 15.01 & 44.83 & 41.68 & 11.79 \\
\hline 13 & 15.01 & 47.90 & 44.32 & 10.31 \\
\hline 14 & 15.01 & 46.15 & 43.69 & 8.57 \\
\hline 15 & 15.01 & 42.78 & 40.88 & 7.32 \\
\hline
\end{tabular}


Table 3. Moisture content of soil sample without SAP

\begin{tabular}{|c|c|c|c|c|}
\hline Time (Days) & $\left.\mathbf{M}_{\mathbf{1}} \mathbf{( g m}\right)$ & $\mathbf{M}_{\mathbf{2}} \mathbf{( g m )}$ & $\mathbf{M}_{\mathbf{3}} \mathbf{( g m )}$ & $\mathbf{W} \mathbf{( \% )}$ \\
\hline 1 & 14.66 & 76.78 & 60.67 & 35.00 \\
\hline 2 & 14.66 & 60.29 & 51.39 & 23.22 \\
\hline 3 & 14.66 & 99.71 & 51.39 & 20.10 \\
\hline 4 & 14.66 & 71.20 & 62.22 & 18.87 \\
\hline 5 & 14.66 & 59.20 & 52.65 & 17.23 \\
\hline 6 & 14.66 & 56.00 & 50.06 & 16.78 \\
\hline 7 & 14.66 & 68.71 & 62.16 & 13.78 \\
\hline 8 & 14.66 & 61.78 & 57.23 & 10.69 \\
\hline 9 & 14.66 & 72.54 & 68.00 & 8.51 \\
\hline 10 & 14.66 & 56.78 & 54.10 & 6.78 \\
\hline 11 & 14.66 & 46.10 & 45.09 & 3.31 \\
\hline 12 & 14.66 & 46.50 & 45.62 & 2.83 \\
\hline 13 & 14.66 & 46.20 & 45.71 & 1.58 \\
\hline 14 & 14.66 & 43.38 & 43.02 & 1.28 \\
\hline 15 & 14.66 & 40.55 & 40.28 & 1.03 \\
\hline
\end{tabular}

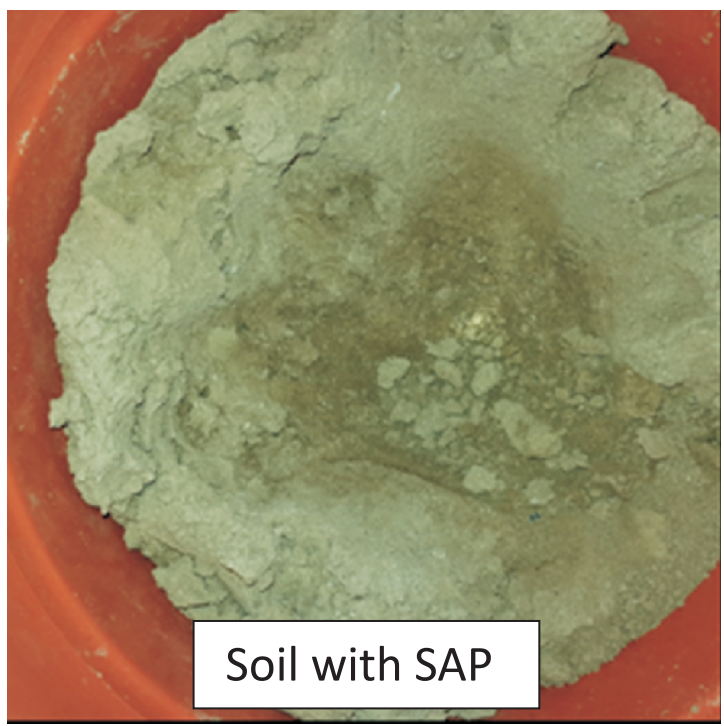

Table 4. Comparison between water content of soil with and without SAP

\begin{tabular}{|c|c|c|}
\hline Days & $\begin{array}{c}\text { Water content of } \\
\text { soil with SAP }\end{array}$ & $\begin{array}{c}\text { Water content of } \\
\text { woil without SAP (W) }\end{array}$ \\
\hline 1 & 35.00 & 35.00 \\
\hline 2 & 32.63 & 23.22 \\
\hline 3 & 31.69 & 20.10 \\
\hline 4 & 28.69 & 18.87 \\
\hline 5 & 26.17 & 17.23 \\
\hline 6 & 23.71 & 16.78 \\
\hline 7 & 20.83 & 13.78 \\
\hline 8 & 18.38 & 10.69 \\
\hline 9 & 16.75 & 8.51 \\
\hline 10 & 14.83 & 6.78 \\
\hline 11 & 13.09 & 3.31 \\
\hline 12 & 11.79 & 2.83 \\
\hline 13 & 10.31 & 1.58 \\
\hline 14 & 8.57 & 1.28 \\
\hline 15 & 7.32 & 1.03 \\
\hline
\end{tabular}

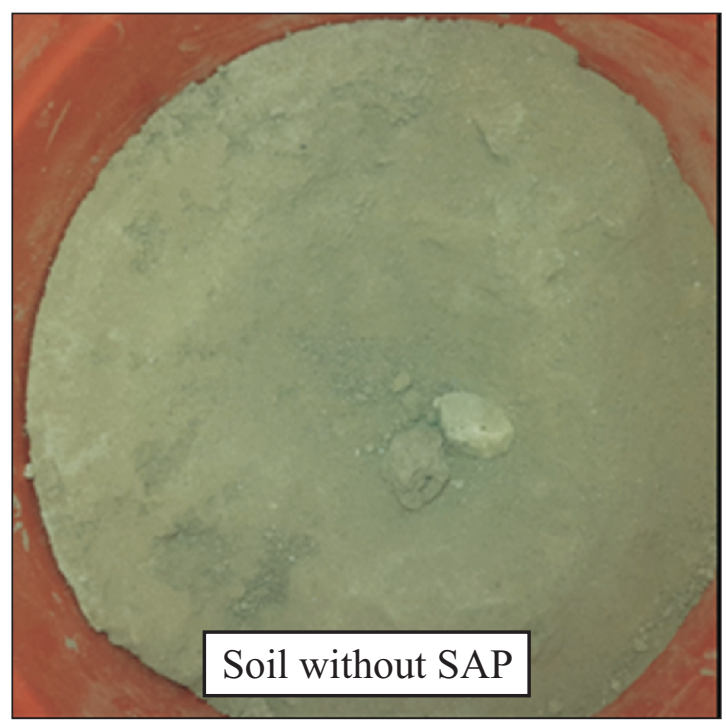

Fig. 4. Moisture content of soil with SAP and without SAP

\subsubsection{Water Requirement In Plants}

Agricultural sector is one of the largest consumers of water. The method of irrigation practiced in large parts of the country is surface irrigation under which crop utilizes only less than one half of the water released and remaining half gets lost in conveyance, application, runoff and evaporation. Water requirement of the plants for agriculture is of outmost importance as agriculture is the basic requirement of all the livelihoods. So, to manage two significant entities water and agriculture, the soil is hybridized and mixed with SAP, as it absorbs and restores large quantity of water for a longer duration. SAP application reduces prolonged irrigation effects on pepper by increasing growth rate, yield, leaf chlorophyll content and relative water content and reduces negative effects of water shortage on plants [10]. Soil sample was mixed with same quantity of water with and without SAP material in two different containers. Two same plants were planted in two different containers with and without SAP material. Both the containers were planted with same plant and given same amount of water initially. The plants that require daily watering and cannot survive if daily watering is not given were chosen. Now the water requirements of plants were checked for the next 16 days and all the progress was monitored closely. The observations were made for the next 16 days and are tabulated in table 5. The water requirement of the plant in soil with SAP material was about 53\% less as compare to the plant planted in the soil without SAP material. Table shows the quantity of watering done in both the samples. The photographs of both the plants are as shown in Fig. 5. 
Table 5. Water requirement of plants with SAP \& without SAP

\begin{tabular}{|c|c|c|c|c|}
\hline $\begin{array}{c}\text { Sr. } \\
\text { No. }\end{array}$ & Date & Time & $\begin{array}{c}\text { Sample A } \\
\text { (Without SAP) }\end{array}$ & $\begin{array}{c}\text { Sample B } \\
\text { (With SAP) }\end{array}$ \\
\hline 1 & $15 / 04 / 2015$ & $5: 30 \mathrm{pm}$ & $1000 \mathrm{ml}$ & $1000 \mathrm{ml}$ \\
\hline 2 & $16 / 04 / 2015$ & $5: 30 \mathrm{pm}$ & --- & --- \\
\hline 3 & $17 / 04 / 2015$ & $5: 30 \mathrm{pm}$ & --- & --- \\
\hline 4 & $18 / 04 / 2015$ & $5: 30 \mathrm{pm}$ & $250 \mathrm{ml}$ & --- \\
\hline 5 & $19 / 04 / 2015$ & $5: 30 \mathrm{pm}$ & $250 \mathrm{ml}$ & --- \\
\hline 6 & $20 / 04 / 2015$ & $5: 30 \mathrm{pm}$ & $250 \mathrm{ml}$ & $250 \mathrm{ml}$ \\
\hline 7 & $21 / 04 / 2015$ & $5: 30 \mathrm{pm}$ & $250 \mathrm{ml}$ & --- \\
\hline 8 & $22 / 04 / 2015$ & $5: 30 \mathrm{pm}$ & $250 \mathrm{ml}$ & --- \\
\hline 9 & $23 / 04 / 2015$ & $5: 30 \mathrm{pm}$ & $250 \mathrm{ml}$ & --- \\
\hline 10 & $24 / 04 / 2015$ & $5: 30 \mathrm{pm}$ & $250 \mathrm{ml}$ & $250 \mathrm{ml}$ \\
\hline 11 & $25 / 04 / 2015$ & $5: 30 \mathrm{pm}$ & $250 \mathrm{ml}$ & --- \\
\hline 12 & $26 / 04 / 2015$ & $5: 30 \mathrm{pm}$ & $250 \mathrm{ml}$ & --- \\
\hline 13 & $27 / 04 / 2015$ & $5: 30 \mathrm{pm}$ & $250 \mathrm{ml}$ & $250 \mathrm{ml}$ \\
\hline 14 & $28 / 04 / 2015$ & $5: 30 \mathrm{pm}$ & $250 \mathrm{ml}$ & --- \\
\hline 15 & $29 / 04 / 2015$ & $5: 30 \mathrm{pm}$ & $250 \mathrm{ml}$ & --- \\
\hline 16 & $30 / 04 / 2015$ & $5: 30 \mathrm{pm}$ & $250 \mathrm{ml}$ & $250 \mathrm{ml}$ \\
\hline
\end{tabular}
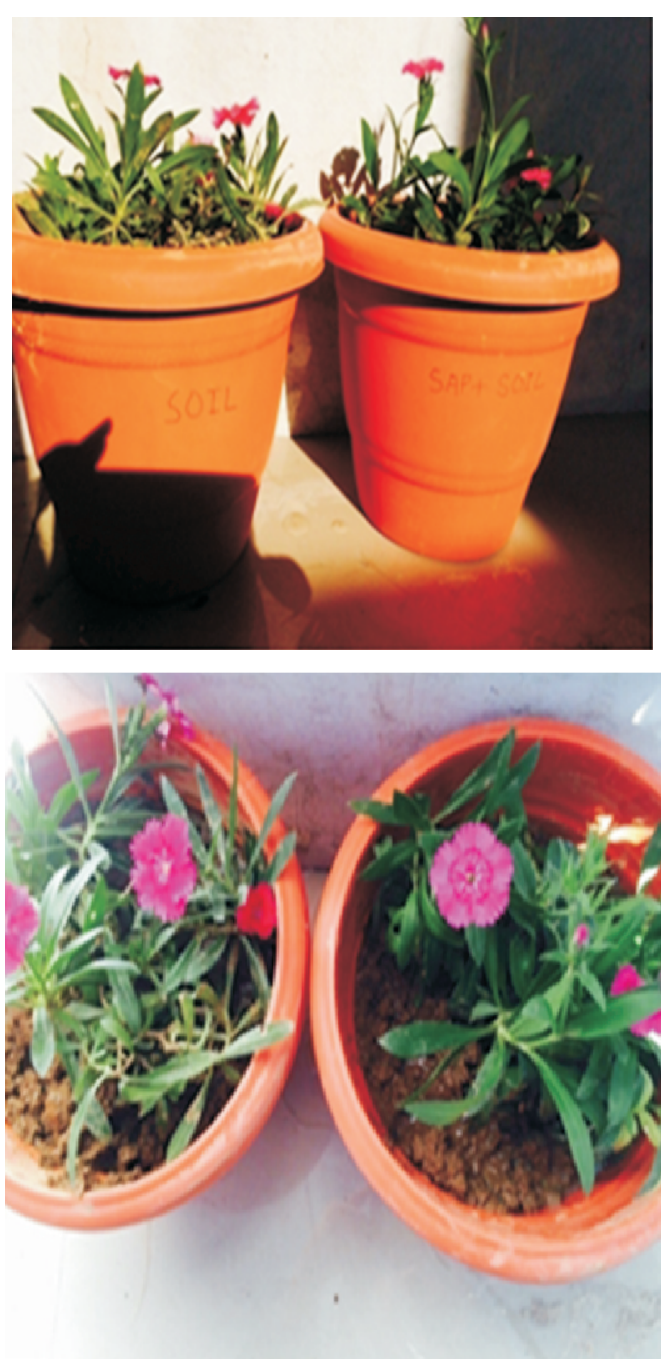

Fig. 5. Plants in Soil with SAP and without SAP

\section{Results and Discussion}

SAP has very large absorption and retention property so it can accumulate large amount of water in its volume. It can absorb natural water and can reach around 100-400 times by its self-weight. In the experimentation conducted for water absorbing capacity, $1 \mathrm{gm}$ of SAP material absorbed $260 \mathrm{gm}$ of tap water. It also has better water-retention capacity. To determine the retention of the SAP material, permeability of SAP materials of different SAP to Water ratio were determined. The value of coefficient of Permeability (k) for different SAP to water ratio ranges in between 0.008 to 0.059 . These values of coefficient of permeability (k) are similar to those of semi-pervious materials. This indicates that the SAP material behaves as semi-pervious.

These two properties of highest water absorption and lowest permeability are favorable for managing low to moderate floods at habitation side and at agriculture farms. The jute bags containing the SAP material can be installed around the doors and windows at habitation side and boundaries of the agriculture farms. During heavy rainfall, the jute bags containing the SAP material will absorb the rain water and will reduce the runoff. Further the swelled jute bags will impede the rain water from entering doors, windows and farmlands. Thus SAP will be helpful to manage low to moderate floods.

Moisture content of soil is the measure of water content of soil. The moisture content of the two soil samples was found by keeping both the soil samples in environmental conditions. Moisture content of soil sample with and without SAP material varies significantly. The moisture content of soil with SAP and without SAP were calculated and it was found that the sample with SAP had around 7\% water content after 15 days and the sample without SAP had around $1 \%$ after 15 days. So the results of water content shows that by adding SAP in the soil the soil has more water content as compared to the soil without SAP. The comparison of soil sample with and without SAP material shows the restoring capacity of SAP material.

SAP can release and absorb water repeatedly, the water which it absorbs can be absorbed slowly by the seed and plant-root, so this will increase soil moisture effectively and decrease the times of irrigation. It is widely used in agriculture and forestry industry, municipal gardening, drought resisting and water preserving, and sand resisting and controlling aspects, and is playing an important role. SAP reduces water depletion and improves plant survival and growth. It will also reduce water runoff and soil erosion. To determine water requirement for agriculture, two same plants were planted in two different containers with and without SAP material. In this water requirement test it was found that the plant with SAP requires around $50 \%$ less water than plant without SAP this shows that by adding SAP in the soil the watering frequency and quantity reduces by $50 \%$.

These two properties of retaining moisture content and reducing water requirement are beneficial for agriculture. 


\section{Conclusion}

The properties of highest water absorption and lowest permeability of SAP material are favorable for managing low to moderate floods at habitation side and at agriculture farms. It is non-toxic and cannot affect the quality of water and is harmless for agriculture. It is very beneficial in agriculture as the moisture content of soil reduces at a slower rate. It is very helpful to the farmers facing problems related to water as it reduces the frequency of watering and the amount of water needed. The results show that the use of the SAP material in agriculture will be beneficial to the farmers and can reduce the problem of water in dry and arid regions. It is biodegradable and eco-friendly as it reduces through natural process of evaporation. Though it is slightly slippery, not easily available in market and is slightly expensive material but is good for the extreme havoc of the environment like heavy rainfall, high temperature, heavy evaporation and water scarcity.

\section{References}

[1] L. O. Ekebafe, D. E. Ogbeifun and F. E. Okieimen, Polymer Applications in Agriculture, Biokemistri 23(2), 2011, p.81-89.

[2] Francesco Puoci, Francesca Iemma, Umile Gianfranco Spizzirri, Giuseppe Cirillo, Manuela Curcio and Nevio Picci, Polymer in Agriculture: a Review, American Journal of Agricultural and Biological Sciences, 3 (1), 2008, p.299-314.

[3] Mohammad J. Zohuriaan-Mehr and Kourosh Kabiri, Superabsorbent Polymer Materials:A Review, Iranian Polymer Journal, 17 (6), 2008, p.451-477.

[4] Miguel Zohuriaan-Mehr, Abel Rodrigues, Fatima Rosa, Superabsorbent polymer for water management in forestry, Agricultural Sciences , 4 (5B), p.57-60,(2013)
5] M. Sadeghi, synthesis of a biocopolymer Carrageenan-g-poly(aam-co-ia)/ Montmorilonite superabsorbent Hydrogel composite, Brazilian Journal of Chemical Engineering, 29,(02), 2012, p.295-305.

[6] Fidelia Nnadi and Chris Brave, Environmentally friendly superabsorbent polymers for water conservation in agricultural lands, Journal of Soil Science and Environmental Management, 2(7), 2011, p.206-211.

[7] Rajiv Dabhi, Neelkanth Bhatt and Bipin Pandit, Super Absorbent Polymers - An Innovative Water Saving Technique for Optimizing Crop Yield, International Journal of Innovative Research in Science, Engineering and Technology, 2(10), 2013, p.5333-5340.

[8] Giuseppe Cannazza, Andrea Cataldo, Egidio De Benedetto, Christian Demitri, Marta Madaghiele and Alessandro Sannino, Experimental Assessment of the Use of a Novel Superabsorbent polymer (SAP) for the Optimization of Water Consumption in Agricultural Irrigation Process, Water, 6, 2014, p.2056-2069.

[9] Roqieh Barihi, Ebrahim Panahpou , Masoud Hossein Mirzaee Beni, Super Absorbent Polymer (Hydrogel) and its Application in Agriculture, World of Sciences Journal, 01(15), 2013, p.223-228.

[10]Mohammad Sayyari and Fardin Ghanbari, Effects of Super Absorbent Polymer A200 on the Growth, Yield and Some Physiological Responses in Sweet Pepper (Capsicum Annuum L.) Under Various Irrigation Regimes, International Journal of Agricultural and Food Research, 1(1), 2012, p.1-11. 